\title{
Progressive Fault Isolation and Grid Restoration Strategy for MTDC Networks
}

\author{
Rui Dantas ${ }^{(}$, Student Member, IEEE, Jun Liang, Senior Member, IEEE, \\ Carlos Ernesto Ugalde-Loo ${ }^{-}$, Member, IEEE, Andrzej Adamczyk, Carl Barker, Senior Member, IEEE, \\ and Robert Whitehouse
}

\begin{abstract}
A multiterminal de (MTDC) grid has a number of advantages over traditional ac transmission. However, dc protection is still one of the main technical issues holding back the expansion of point-to-point de links to MTDC networks. Most dc protection strategies are based on dc circuit breakers; however, DCCBs are still under development and their arrival to the market will come at an unclear time and cost. Conversely, ac circuit breakers (ACCBs) are readily available and represent a more economic alternative to protect dc networks. Following this line, a protection strategy for MTDC grids is proposed in this paper. This uses ACCBs for de fault current clearing and fast de disconnectors for fault isolation. The faulty link is correctly discriminated and isolated while communication links are not required. This strategy contributes to a reduced network outage period as the nonfaulty links are out of operation for a relatively short period of time and are restored in a progressive manner. The effectiveness of the proposed strategy is tested in PSCAD/EMTDC for pole-to-ground and pole-to-pole faults.
\end{abstract}

Index Terms-HVDC transmission, MTDC network, power systems de protection, fault discrimination, ac circuit breakers.

\section{INTRODUCTION}

$\mathbf{T}$ HE development of multi-terminal dc (MTDC) networks brings several benefits. These include the possibility of connecting islands to mainland networks, a wider access to power markets and an increase in the security of electricity supply. For example, a meshed MTDC grid in the North Sea will facilitate the exchange of reserves between the UK, Nordic and Northern European countries, the integration of offshore wind farms and access to a wider and more economic power market [1]. However, a number of technical challenges are expected. These include the coordinated control of converters from multiple vendors, limitations on the insulation level of dc cables, current flow control in dc grid protection, and regulation and standardisation issues [2].

A major technical barrier preventing the development of reliable MTDC grids is dc fault protection. This topic can be di-

Manuscript received February 11, 2017; revised May 12, 2017; accepted June 8, 2017. Date of publication August 9, 2017; date of current version March 22, 2018. Paper no. TPWRD-00241-2017. (Corresponding author: Rui Dantas.)

R. Dantas, J. Liang, and C. E. Ugalde-Loo are with the Cardiff University, Cardiff CF24 3AA, U.K. (e-mail: DantasR@cardiff.ac.uk; LiangJ1@ cardiff.ac.uk; Ugalde-LooC@ @ardiff.ac.uk).

A. Adamczyk, C. Barker, and R. Whitehouse are with the GE's Grid Solutions, Stafford ST17 4LX, U.K. (e-mail: Andrzej.Adamczyk@ge.com; Carl.Barker1@ge.com; Robert.Whitehouse@ge.com).

Color versions of one or more of the figures in this paper are available online at http://ieeexplore.ieee.org.

Digital Object Identifier 10.1109/TPWRD.2017.2720844 vided into dc protection devices and dc protection strategies [3]. Devices that will facilitate dc grid protection include dc circuit breakers (DCCBs) and converters with fault current blocking capability [4], [5]. Although DCCBs have been thoroughly investigated over the last years, the technology is commercially available up to medium voltage range applications [6] but still very limited for HVDC applications [7]. Converters with fault blocking capability based on full-bridge submodules are commercially available and their adoption could be beneficial for schemes using overhead transmission lines [8]. However, the major drawbacks of these converters arise from the higher conduction losses and investment cost in comparison to conventional converters based on half-bridge submodules.

$\mathrm{AC}$ circuit breakers (ACCBs) have been employed to protect point-to-point dc links [7] and MTDC grids [9]. Although they constitute a mature technology, the main disadvantages of using ACCBs are their relatively long interruption time and the temporary outage of the whole dc network.

The use of ACCBs for the protection of MTDC grids has been examined in the literature. In the "handshaking" method [10], fault clearance is achieved by the opening of ACCBs and fault isolation is achieved using fast dc disconnectors (FDs) when the current becomes zero. Grid restoration occurs with ACCBs reclosing actions. A fixed time delay (e.g., $100 \mathrm{~ms}$ ) due to ACCB operation is considered as part of the process. However, if the fault is not isolated within that period, the grid restoration process may re-initiate the dc fault. To avoid this issue, a larger delay would be required at the expense of increasing the outage time of an MTDC grid -which may not be desirable.

In order to reduce the outage time of an MTDC grid protected by ACCBs, a methodology is proposed in this paper. The algorithm, referred here as progressive protection strategy (PPS), uses ACCBs to clear dc faults and FDs to isolate dc links. The PPS exploits the possibility of restoring parts of the network at different times. Hence, power restoration might occur in a part of the grid even if the faulty link is not completely isolated from the dc grid. This way, the power transfer between ac systems connected through de links occurs faster in comparison to conventional methods. Reduction of the MTDC grid outage time brings additional benefits, including a reduction in the energy not supplied, and a reduced impact on stability and frequency deviations of adjacent ac systems [1], [11], [12]. Additionally, fault discrimination is achieved locally and link communication channels are not required. 
The application of the PPS in large MTDC grids may not be suitable as it would lead to a power in-feed loss at a scale that might not be acceptable to transmission system operators. However, it represents a viable and economic option to protect smaller sections of a large MTDC grid that is segregated into small zones by DCCB operation [13].

The rest of the paper is structured as follows. Section II describes the algorithm of the proposed protection strategy. Section III describes the modeling of the MTDC network. Section IV shows simulation results for pole-to-pole (P2P) and pole-to-ground (P2Gnd) faults. Section V discusses back-up protection, with Section VI addressing the performance of the proposed algorithm against methods found in the literature. The paper ends with a conclusion in Section VII.

\section{Progressive Protection Strategy}

The PPS algorithm, if adopted, should be implemented in every busbar unit of an MTDC grid. Each unit will exchange data with the neighboring dc relays, converter station and ACCB. A busbar unit receives current and voltage measurements from local dc relays, runs the PPS algorithm and, as necessary, sends opening/closing orders to the associated ACCB and FDs together with blocking/de-blocking orders to the associated converter. In the case of a dc fault, the PPS will detect it, discriminate it and initiate a protection sequence of these units. This process is described in detail in the following subsections. It should be highlighted that since communication protocols for HVDC stations are yet to be standardized [3], their discussion is out of the scope of this paper.

\section{A. Fault Detection and Clearance}

The fault detection criterion is based on link overcurrent or undervoltage. An overcurrent or undervoltage typically takes place within a very short time (e.g., $1 \mathrm{~ms}$ ) after the arrival of transient waves. The criterion is defined as:

$$
I_{p / n}>1.2 \times I_{n o m} \text { or }\left|V_{p / n}\right|<0.8 \times V_{n o m}
$$

where subscript $p / n$ represents the positive or negative pole and subscript nom the nominal value of current or voltage. The fault detection thresholds have a deviation of 0.2 p.u. from the nominal values. This considers an operational deviation component of 0.1 p.u., which is, for example, an acceptable deviation for a temporary undervoltage [14]. Additionally, a safety margin of 0.1 p.u. is included to consider potential noise and precision errors from sensors. This way, the overall fault detection threshold of 0.2 p.u. is added to (or subtracted from) the overcurrent or undervoltage thresholds. These thresholds are expected to lead to fault detection independently of the dc grid configuration.

After fault detection, three actions occur in parallel: the blocking of the associated converter (if in de-blocked mode), the opening of the associated ACCB, and fault discrimination. The converter blocking action protects internal power electronic components while preventing submodule capacitors discharging to the dc fault. This action does not interrupt the fault current path as an ac infeed occurs through the diodes in half-bridge based converters. In addition, a converter blocks in the case of overcurrent detection in the positive or negative pole, regardless

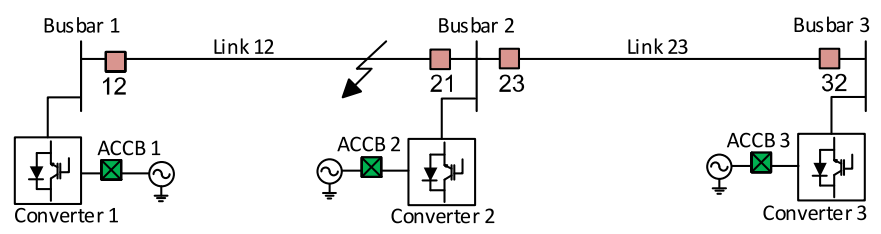

Fig. 1. Selection of potential FDs with (a) dc current curves and (b) dc current derivative function with positive and negative threshold.

of the orders from the PPS. Fault interruption occurs with the opening of ACCBs. Both of these orders have a delay of $2 \mathrm{~ms}$ assumed for data acquisition, processing, coding and decoding of analogue-digital signals, and data transfer.

\section{B. Fault Discrimination Based on Current}

The fault discrimination process relies on the identification of 'potential' and 'non-potential' FDs. 'Potential' FDs include those placed in the faulty link and a few in non-faulty links. This implies that the fault location is partially discriminated at this stage. 'Non-potential' FDs are identified as those placed in non-faulty links.

Identification of the 'potential' FDs is based on two criteria employing the sign and magnitude of the dc fault current. Current is assumed as positive if it flows from a busbar to a dc link. After the start of a fault, if the sign of the derivative of the dc current on a link $L$ becomes positive, the fault might be internal to that link as determined by (2). Conversely, if the sign becomes negative, the fault is external to that link, as determined by (3). Notice that the classification of 'potential' and 'non-potential' FD occurs with the first transgression of either threshold $d I_{t r h}$ or $-d I_{t r h}$.

$$
\begin{aligned}
\frac{d I_{L}}{d t}>d I_{t r h} \\
\frac{d I_{L}}{d t}<-d I_{t r h}
\end{aligned}
$$

In (2) and (3), the threshold $d I_{t r h}$ is considered to analyze the dc current sign while neglecting potential noise. The threshold is assumed to be 0.03 p.u./ms, which was selected after performing extensive computer simulations. It should be emphasized that this value is larger than the observed noise. Without it, the current sign criterion might not be applicable as the potential measured noise may lead to random positive or negative values of dc current derivatives.

It should be noticed that the current derivative sign may be positive in more than one link connected to the same busbar. To identify the most suitable 'potential' FD, a current magnitude criterion is used. The FD that exhibits the largest positive current derivative is defined as 'potential'. The remaining FDs associated to the same busbar unit are classified as 'non-potential'. In the case of parallel dc links, multiple FDs may be classified as 'potential'. In the unlikely case that a dc current does not transgress thresholds $d I_{t r h}$ or $-d I_{t r h}$, the FDs are classified as 'non-potential' by default.

Fig. 1 illustrates a simple three-terminal dc network. Considering a fault on Link 12, Busbar Unit 2 selects one 'potential' FD based on current measurements on Relays 21 and 23. Fig. 2 


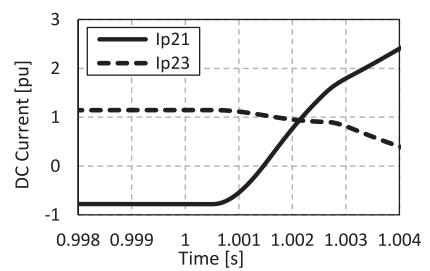

(a)

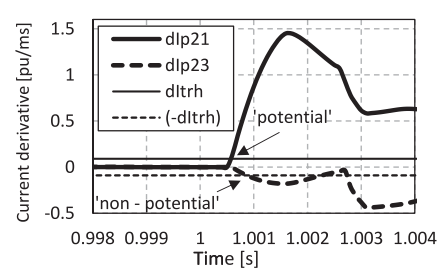

(b)
Fig. 2. Selection of potential FDs with (a) dc current curves and (b) dc current derivative function with positive and negative threshold.

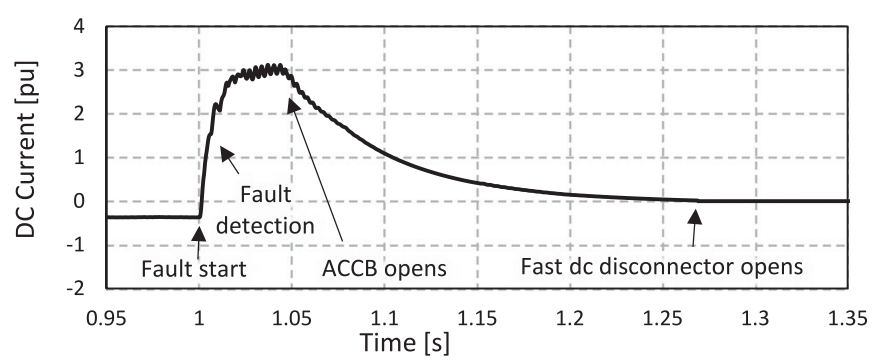

Fig. 3. Generic dc fault current behavior.

illustrates the dc line currents on the positive poles of the two links ('Ip21' and 'Ip23') and their derivatives ('dIp21' and 'dIp23').

The positive sign of the current derivative ' $\mathrm{d} 21 \mathrm{p}$ ' indicates a current increase from Busbar 2 to Link 12. Hence, according to (2), FD 21 is classified as 'potential' when current derivative 'dIp21' transgresses $d I_{t r h}$. On the other hand, according to (3), FD 23 is classified as 'non-potential' when 'dIp23' transgresses $-d I_{t r h}$. According to this criterion, FDs 12 and 32 are also classified as 'potential'.

\section{Fault Isolation}

Following ACCBs opening operations, dc fault current $I_{d c}$ starts to decay to zero. The decaying time is dependent on the fault current $I_{0}$ at the clearance instant and on the equivalent resistance $R$ and inductance $L$ of the fault discharge path. This can be mathematically expressed as:

$$
I_{d c}(t)=I_{0} e^{-\frac{R}{L} t}
$$

The time constant $(L / R)$ is larger for a low impedance fault, which constitutes the most common fault type [15]. Once the dc line currents decay below the residual breaking capability of the FDs, all of these devices open. This operation is achieved following a period of tens of milliseconds to seconds.

Fig. 3 illustrates a generic dc fault current profile. In this case, converter blocking occurs just after fault detection. The ACCB opening occurs with a delay of approximately $50 \mathrm{~ms}$ after fault detection. Once the dc fault decays to nearly zero, which in this case occurs approximately $250 \mathrm{~ms}$ after the start of the fault, the FDs are able to open.

The decaying behavior of the dc fault current delays the isolation actions and, consequently, holds up the grid recovery process. This is a major constraint for MTDC grid equipment relying on ACCBs for protection. However, this shortcoming is partially mitigated by the PPS by reducing the overall network outage time.

\section{Grid Restoration: Reclosing 'Non-Potential' FDs}

Once all FDs associated to a busbar unit are opened, the discriminative reclosing operation starts. Grid restoration occurs with three actions. Firstly, 'non-potential' FDs receive a reclosing order once a 'potential' FD opens. FDs are required to remain in open mode for a minimum period of time $\Delta t_{i s}$. In order to avoid the reclosing of an FD before the opening of the FD at the other link end, a time lag is considered. This period of time is assumed as $10 \mathrm{~ms}$ in case of $\mathrm{P} 2 \mathrm{P}$ faults and as $40 \mathrm{~ms}$ for P2Gnd faults. The reason for a larger waiting time in P2Gnd faults is due to an additional overvoltage suppression operation. This action is performed using a resistive discharge circuit whose principles are detailed in Section IV-B1.

Secondly, an ACCB receives a reclosing order after the reclosing operation of any FD associated to the same busbar unit. The latter action restores the dc side voltage in non-faulty dc links.

Lastly, a converter receives a de-blocking order once the following criteria are met:

1) The ACCB is closed;

2) The P2P voltage has recovered to above 0.7 p.u.;

3) The positive and negative P2Gnd voltages have recovered to \pm 0.3 p.u.

The converter will be de-blocked after the ACCB reclosing operation is concluded to prevent harmful switching transients. With these requirements, the de-blocking starts typically $\approx 10 \mathrm{~ms}$ after an ACCB reclosing operation. The resuming operation of ACCBs and converters allows the re-establishment of the nominal voltage in non-faulty links of the dc network.

\section{E. Fault Discrimination Based on Voltage}

Voltage magnitudes are considered for discriminating 'potential' FDs placed at faulty and non-faulty links. The 'potential' FDs are classified as external to the faulty link if the dc voltage meets one of two possible criteria. The first criterion is based on dc link voltage recovery:

$$
V_{p n}>0.9 \text { p.u., } V_{p}>0.3 \text { p.u., and } V_{n}<-0.3 \text { p.u. }
$$

where $V_{p n}$ is the $\mathrm{P} 2 \mathrm{P}$ link voltage, $V_{p}$ the positive pole voltage and $V_{n}$ the negative pole voltage. The thresholds in (5) have been defined after analyzing the dc voltage recovery following an extensive number of simulations of the test system. These values should be bespoke for each specific MTDC grid project.

The second criterion is based on the overvoltage suppression in non-faulty links, which is necessary for P2Gnd faults (see Section IV-B1). This discrimination criterion is based on the overvoltage drop to zero, which occurs at one link end with the aid of a discharging circuit associated to 'non-potential' FDs. In the other link end, if a 'potential' FD is present, it is discriminated (i.e., it is as external to the faulty link). The overvoltage suppression does not occur quickly at the faulty link as the FDs at both link terminals are classified as 'potential'. 


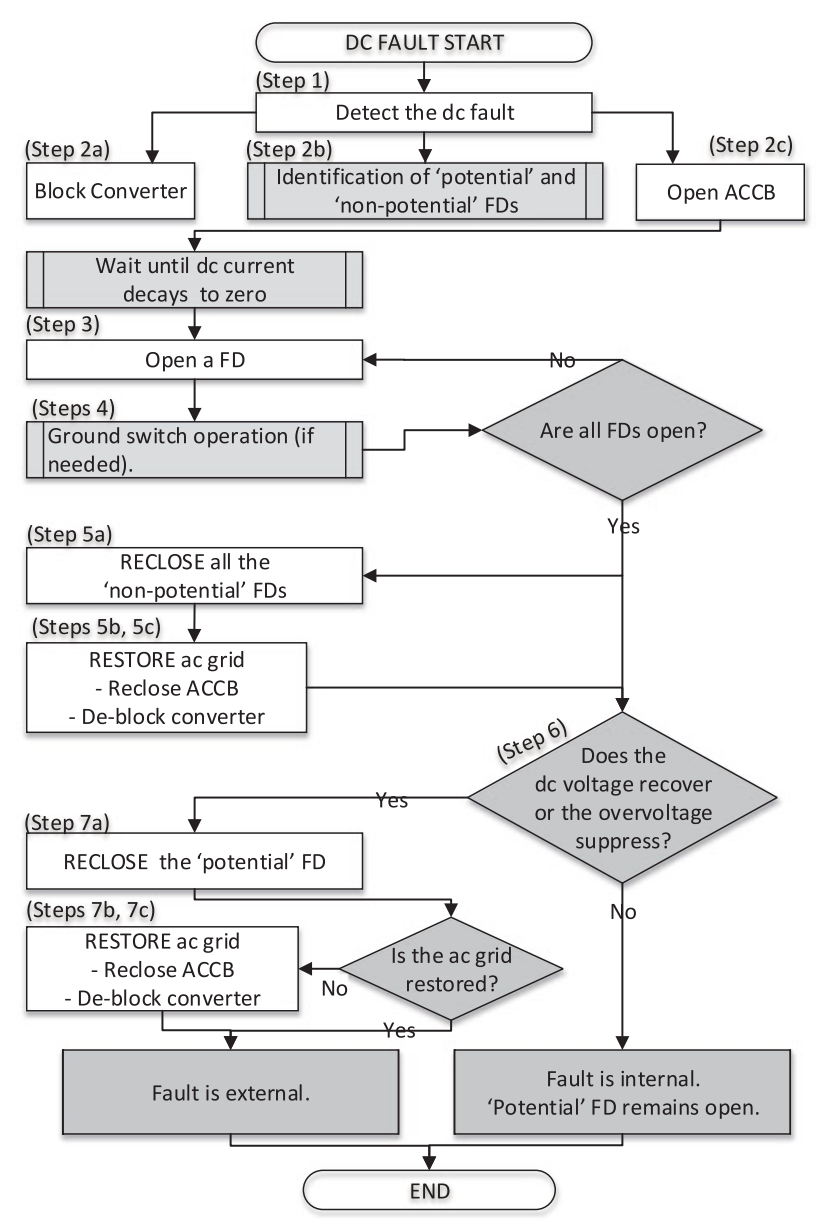

Fig. 4. Detailed flowchart of the PPS for an individual busbar unit.

In summary, if the dc voltage recovers in a link where a 'potential' FD is placed, the fault is external to such a link irrespectively of the type of fault. If the voltage does not recover, then the fault is internal to such link.

\section{F. Grid Restoration: Reclosing 'Potential' FDs}

The 'potential' FDs classified as external to the faulty link (see Section II-E) receive a reclosing order. If the ac grid has not yet been restored, the actions at this stage include the ACCB reclosing and converter de-blocking operation.

At this point, all ACCBs have been reclosed, the converters have been de-blocked and the FDs placed at non-faulty links have been reclosed. The faulty link remains isolated by the open mode of the 'potential' FDs placed at each link end.

\section{G. Summary of the PPS}

Fig. 4 shows a comprehensive flowchart of the PPS. The sequence of actions is summarized as follows:

1) DC fault detection.

2) Initial protective actions:

a) Converter blocking order;

b) Identify 'potential' and 'non-potential' FDs;

c) ACCB opening order.

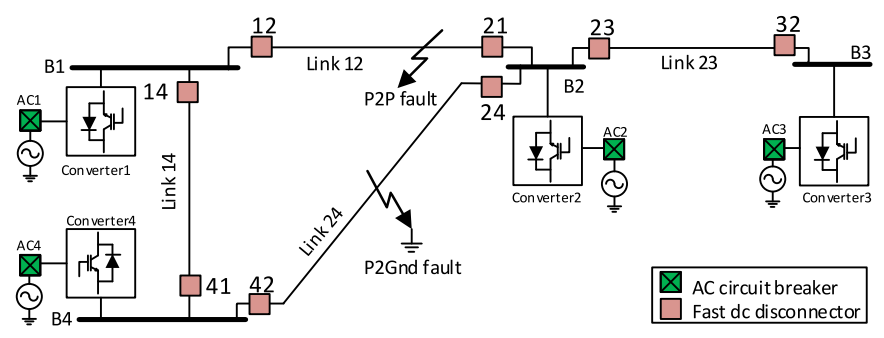

Fig. 5. MTDC grid case study showing the location of the fault scenarios.

TABLE I

CABLE PARAMETERS

\begin{tabular}{lccccc}
\hline \hline Layer & Material & $r[\mathrm{~mm}]$ & $\rho[\Omega / \mathrm{m}]$ & $\varepsilon_{r}[-]$ & $\mu_{r}[-]$ \\
\hline Core & Copper & 25.2 & $1.72 \times 10^{-8}$ & 1 & 1 \\
Insulation & XPLE & 45.2 & - & 2.3 & 1 \\
Sheath & Lead & 48 & $2.2 \times 10^{-7}$ & 1 & 1 \\
Insulation & XPLE & 53 & - & 2.3 & 1 \\
\hline \hline
\end{tabular}

3) FDs opening operation.

4) Ground switch operation if overvoltage is detected.

5) Grid restoration I:

a) Reclose 'non-potential' FDs;

b) Reclose ACCB;

c) De-block converter.

6) Evaluate voltage restoration.

7) Grid restoration II:

a) Reclose 'potential' FDs;

b) Reclose ACCB (if open);

c) De-block converter (if blocked).

\section{DC GRID CASE STUDY}

The four-terminal dc network shown in Fig. 5 is used to assess the proposed algorithm. The system has a symmetrical monopole configuration with a P2P dc voltage of $400 \mathrm{kV}$. A halfbridge modular multi-level converter (MMC) is employed. The detailed equivalent model (DEM), classified as Type 4 model by CIGRE [6], is used. This is suitable for transient studies in which internal access to submodules is not required.

The dc grid operation principle is based on a master-slave scheme, where Converter 2 operates in a dc voltage mode while the remaining converters employ an active power mode. Irrespectively of the adopted scheme for converter control, the performance of the PPS algorithm following fault detection is expected to be similar. The reader is referred to [6] for a more detailed description of the control schemes.

Underground cables and overhead lines (OHLs) are employed as dc links. These are modeled as frequency dependent (phase) models and are based on the tower configuration and cable design of two real projects [16], [17]. The dc voltage is scaled to $\pm 200 \mathrm{kV}$ as suggested in [18]. The parameters of the underground cables are provided in Table I, where $r$ represents the outer radius, $\rho$ the resistivity, $\varepsilon_{r}$ the relative permittivity and $\mu_{r}$ the relative permeability.

Grounding points are placed on the ac side by means of a star inductance with a high impedance earthing arrangement 
TABLE II

SYSTEM PARAMETERS

\begin{tabular}{lcc}
\hline \hline Parameter & Value & Unit \\
\hline Converter model & DEM, Type 4 & {$[-]$} \\
DC voltage & \pm 200 & {$[\mathrm{kV}]$} \\
Submodules per arm & 200 & {$[-]$} \\
Submodule resistance (on) & 0.908 & {$[\mathrm{~m} \Omega]$} \\
Converter arm inductor & 100 & {$[\mathrm{mH}]$} \\
Link end inductor & 10 & {$[\mathrm{mH}]$} \\
FD operation & 10 & {$[\mathrm{~ms}]$} \\
ACCB operation time & $\approx 50$ & {$[\mathrm{~ms}]$} \\
\hline Link 12 OHL & 200 & {$[\mathrm{~km}]$} \\
Link 23/24/14 Cable & $100 / 150 / 100$ & {$[\mathrm{~km}]$} \\
\hline Per Unit Base Voltage & 400 & {$[\mathrm{kV}]$} \\
Per Unit Base Current & 2 & {$[\mathrm{kA}]$} \\
\hline \hline
\end{tabular}

[19]. Additionally, the cable sheath layer is connected to ground via a low ohmic path. The second conductor sheath (armour) is neglected in the model due to the influence of the ground connection of the first sheath, as detailed in [20].

In line with the proposed PPS algorithm, ACCBs are the fault interruption devices considered in this study. These make use of the zero crossing point at each cycle to open. The ACCB operation takes approximately 2.5 ac cycles $(50 \mathrm{~ms})$. ACCBs include pre-inserted soft-start resistors which reduce the magnitude of the inrush currents. These resistors are not necessary for the correct operation of the PPS but shall be present for high-voltage applications.

Due to the relatively slow operation of $\mathrm{ACCBs}$, converters based on half-bridge submodules must be able to temporarily withstand high fault currents (e.g., 3 p.u.). Design considerations that reduce potential high currents include the large rating of arm inductors, which reduces the current rate of change and the current magnitude at the interruption instant [21]. To protect the converter's diodes, a protective bypass switch and/or a thyristor is additionally fired during the fault, allowing most of the current to flow through the bypass device and not through the diodes [6]. The short-circuit ratio (SCR) also plays a role on the ac current infeed during a dc fault. A reduced SCR leads to a smaller ac current infeed through the converter's arms [22]. Thus, with a proper design, converters are able to withstand high currents due to a de fault.

FDs are off-load devices with a short operation time of a few to tens of milliseconds. These can be designed following two approaches. Firstly, a mechanical switch (such as an ACCB) could be used, which is able to open within a few tens of milliseconds. Secondly, an ultra-fast mechanical switch as in [23] could be used, which is able to open within $2 \mathrm{~ms}$. In order to have a compromise between these two approaches, a $10 \mathrm{~ms}$ operational time is assumed. In terms of current interruption, a residual braking capability is expected. In this paper, the residual braking capability of FDs is assumed as $30 \mathrm{~A}$. A summary of the system parameters is given in Table II.

\section{Simulation Results}

Two fault cases are used to test the PPS (see Fig. 5). In the first case, a P2P fault occurs on Link 12, 20 km away from dc Relay

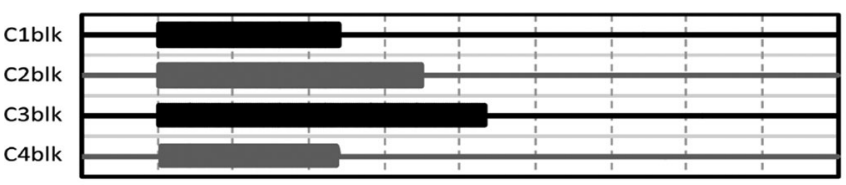

(a)

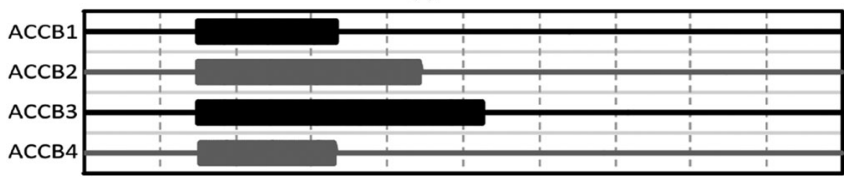

(b)

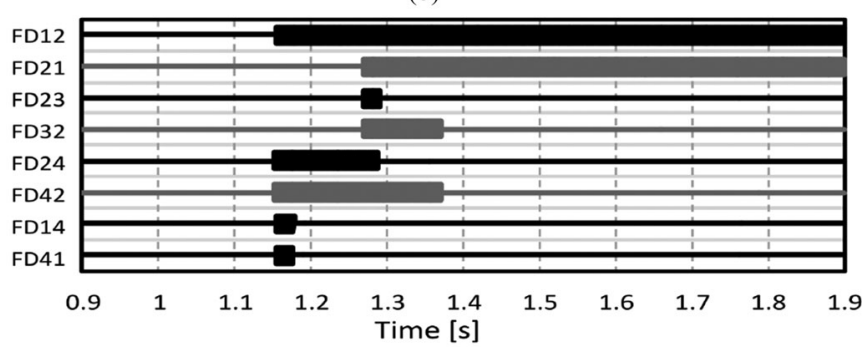

(c)

Fig. 6. State of (a) converters, (b) ACCBs and (c) FDs for the P2P fault case

21 with a fault impedance of $0.5 \Omega$. In the second case, a P2Gnd fault occurs in the middle of Link 24 with a fault impedance of $5 \Omega$. The fault location or fault impedance value does not affect the behavior of the PPS as the algorithm is only sensitive to the fault detection criteria (overcurrent or undervoltage in (1)) and FD classification based on the rate of change of current (in (2) and (3)).

\section{A. Pole-to-Pole Fault}

A P2P fault occurs at $1 \mathrm{~s}$ and is detected within $1 \mathrm{~ms}$ after the arrival of transient waves. Considering that link propagation delay occurs, fault detection is achieved in all dc relays within $3 \mathrm{~ms}$ after the start of the fault. This is Step 1 in Fig. 4. Fig. 6 illustrates a time window of the whole fault clearance, isolation and grid restoration process. The thick lines represent the blocking of converters, opening of ACCBs and opening of FDs. Fig. 7 shows the positive pole dc current and voltage in a number of dc relays and the current output of the converters. As it can be seen in Fig. 6(a), the converters are blocked within a few milliseconds after the start of the fault (Step 2a in Fig. 4).

In the identification process (Step 2b), each busbar unit classifies the FDs as 'potential' or 'non-potential'. The 'potential' FDs, which exhibit a positive sign of current (as defined by (2)), are FDs 12, 21, 32 and 42. In Fig. 7(a), the dc currents that have an increasing behavior shortly after $1 \mathrm{~s}$ are associated with 'potential' FDs. Curve 'I14p', associated to FD 14, has a decreasing behavior which relates to a negative sign of the current derivative (as given by (3)). With this criterion, FDs 14, 41, 23 and 24 are classified as 'non-potential'. The opening order of ACCBs occurs after fault detection (Step 2c) but the opening operation occurs only at $\approx 55 \mathrm{~ms}$ following the dc fault [see Fig. 6(b)]. From this instant, the dc current starts to decay to zero at the dc links and converters, as shown in Fig. 7(a) and (c). 

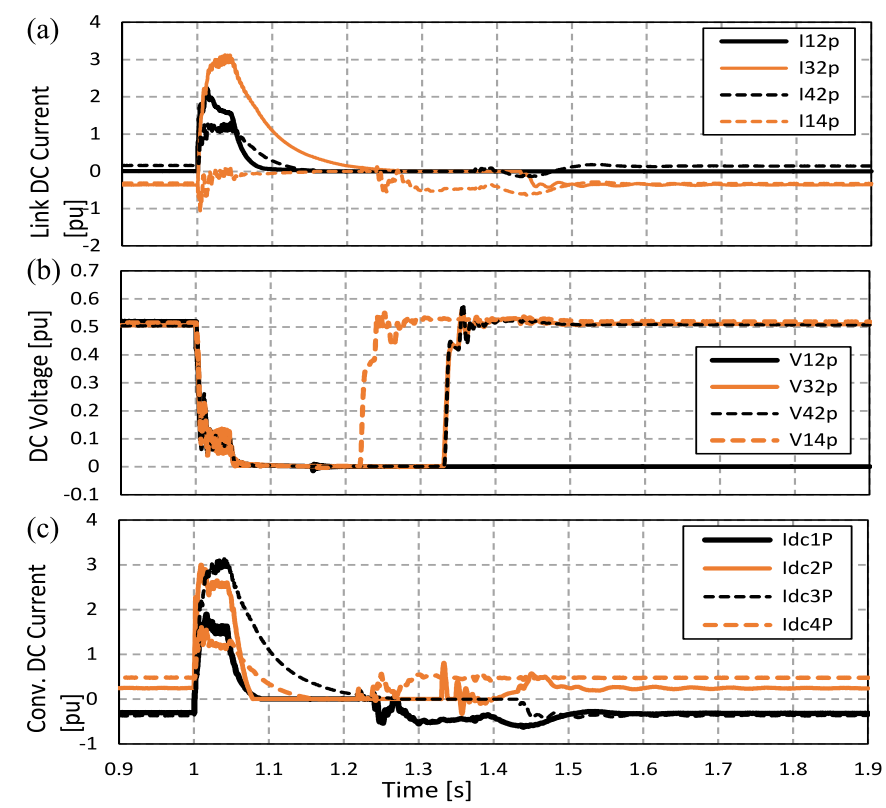

Fig. 7. (a) DC link currents, (b) dc links voltage and (c) dc converter current for the P2P fault case.

In Step 3, the opening operation of FDs occurs once the dc fault current decays to nearly zero. The opening and reclosing times are illustrated in Fig. 6(c). For instance, 'FD14' in Fig. 6(c) opens once 'I14p' in Fig. 7(a) reaches a nearly zero magnitude, which occurs at $\approx 1.15 \mathrm{~s}$. However, 'FD21', associated with dc current 'I21p', is able to open only at a later stage at $\approx 1.38 \mathrm{~s}$.

Step 4 is not applicable for P2P faults as there is no dc overvoltage. This will be described in the P2Gnd fault case.

All FDs associated to Busbar Units 1 and 4 (FDs 12, 14, 41 and 42 ) open at $\approx 1.15 \$ \mathrm{~s}$ as shown in Fig. 6(c). As a result, Step 5 starts in these busbars. Firstly, 'non-potential' FDs 14 and 41 receive a reclosing order (Step 5a). This leads to the restoration of Link 14. Then, in Step 5b, ACCBs 1 and 4 reclose at $\approx 1.25 \mathrm{~s}$ [see Fig. 6(b)]. From the reclosing of the pre-inserted resistor at ACCBs 1 and 4, a dc current flows through the uncontrolled diodes and rises the dc voltage of Link 14 to 'V14p' in Fig. 7(a). In Step 5c, Converters 1 and 4 de-block [see Fig. 6(a)]. At this instant $(\approx 1.25 \mathrm{~s})$, the power flow on Link 14 restores as evidenced by 'I14p' and 'V14p' in Fig. 7(a) and (b). Restoration of Link 14 occurs before isolation of faulty Link $12(\approx 1.28 \mathrm{~s})$.

At $\approx 1.28$ s, FDs 21,23 and 32 open [see Fig. 6(c)]. As all FDs associated to Busbar Unit 2 are open, Step 5 starts (this step has already been concluded for Busbar Units 1 and 4). At Busbar Unit 2, 'non-potential' FDs 23 and 24 reclose (Step 5a), ACCB 2 recloses (Step 5b), and Converter 2 de-blocks (Step 5c). These actions are represented by the changes of thick to thin lines of 'FD23', 'FD24', 'ACCB2' and 'C2blk' in Fig. 6. Such actions lead to voltage restoration at non-faulty Links 23 and 24 at $\approx 1.35$ s [see Fig. 7(b)]. At Busbar Unit 3, Step 5 is not applicable as there are no 'non-potential' FDs.

Step 6 relates to the discrimination of 'potential' FDs placed at faulty links (FDs 12 and 21) and at non-faulty links (FDs 32 and 42). Voltage restoration occurs next to 'potential' FDs 32 and 42 as seen by 'V32p' and 'V42p' at $\approx 1.35 \mathrm{~s}$ in Fig. 7(b).

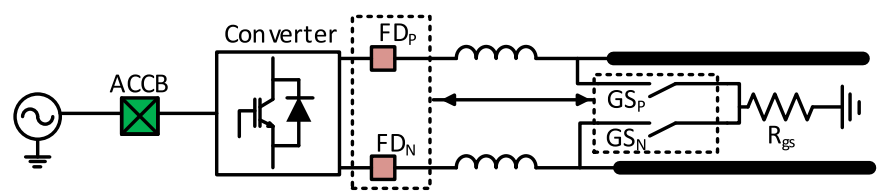

Fig. 8. Configuration of a ground switch.

As result, Step 7 starts at Busbar Units 3 and 4 (associated to FDs 32 and 42, respectively).

Step 7 relates to grid restoration actions. In Step 7a, 'potential' FDs 32 and 42 reclose $(\approx 1.38 \mathrm{~s}$ in Fig. 6(c)). These are discriminated in Step 6. At this instant, the protection algorithm terminates in Busbar Unit 4 as all devices are reclosed and Converter 4 is de-blocked. In Busbar Unit 3, the ac grid is not yet restored. Hence, in Step 7b ACCB 3 recloses and in Step 7c Converter 3 de-blocks ('ACCB3' and 'C3blk' in Fig. 6(b) and (a)). Following these actions, the protection algorithm terminates for Busbar Unit 3. In Busbar Units 1 and 2, the voltage does not restore on Link 12 and the fault is discriminated as internal to their 'potential' FDs 12 and 21.

By the end, only those FDs placed on the faulty link are in open state. The fault is discriminated and the non-faulty part of the dc grid is recovered in a progressive manner. Link 14 is restored at approximately $1.25 \mathrm{~s}$ while remaining non-faulty links are restored at approximately $1.35 \mathrm{~s}$.

\section{B. Pole-to-Ground Fault}

A P2Gnd fault in a symmetrical monopole network causes the voltage collapse in the faulty pole while the voltage in the healthy pole moves towards twice the nominal value. The overvoltage and voltage unbalance must be suppressed before the re-start up of the dc network. Although overvoltage decays naturally to zero, this process can last for hundreds of milliseconds to seconds. In order to accelerate this process, resistive discharge circuits are considered at each link end. These have the function to discharge quickly the energy from the pole exhibiting overvoltage to ground.

1) Resistive Discharge Circuits: These are based on switches connecting each pole to ground through a resistor, as shown in Fig. 8. A ground switch $\left(G S_{P}, G S_{N}\right)$ and a discharging resistor $\left(R_{g s}\right)$ are considered at each link end.

Ground switches are normally in an open state. After the opening operation of the fast dc disconnector (at both the positive and negative poles), the switch closes if a P2Gnd fault is detected and if it is associated to a 'non-potential' disconnector (as in Step 2b in Fig. 4). The switches re-open once the dc current flowing through the discharge resistor decays below a residual value. Once the switch re-opens, the operation of the associated dc disconnector is resumed.

The switches opening/closing actions have a delay of $10 \mathrm{~ms}$. The smaller the size of resistor $R_{g s}$, the shorter the time it requires to discharge the link energy at the expense of a higher peak current. Assuming a maximum peak of $4 \mathrm{kA}$, a $50 \Omega$ resistor is considered.

2) P2Gnd Fault Case: The fault starts at $1 \mathrm{~s}$. Fault detection is achieved within a few milliseconds after the start of 


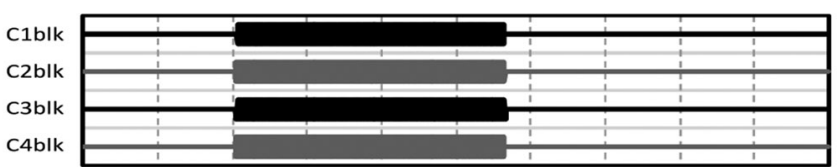

(a)

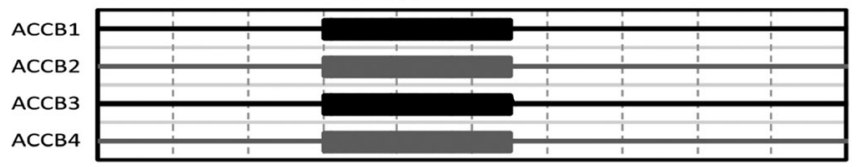

(b)

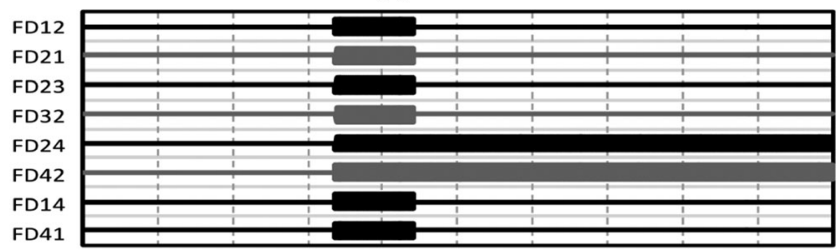

(c)

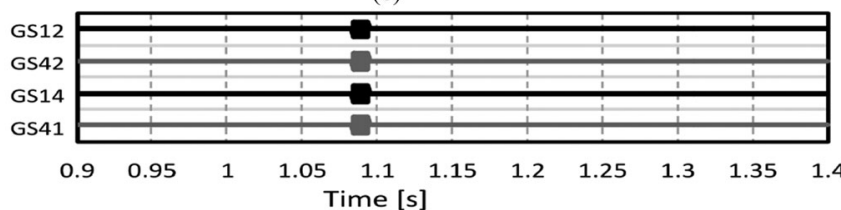

(d)

Fig. 9. State of (a) the converters, (b) ACCBs, (c) FDs and (d) grounding switches for the P2Gnd fault case.

the fault (Step 1 in Fig. 4). As a consequence, the converter blocking orders (Step 2a), the identification of 'potential' and 'non-potential' FDs (Step 2b) and the ACCB opening orders (Step 2c) are set. Fig. 9 shows the device operations during the fault clearance, isolation and grid recovery actions. These include the blocking of converters, the opening of ACCBs, opening of FDs and the closing operation of a number of ground switches. Fig. 10 shows a number of signals during application of the protection strategy, including current and voltage measurements in a number of dc relays and the dc current output at each converter.

In Step 2b, FDs 14, 24, 32 and 42 are identified as 'potential'. These exhibit a positive sign of current derivative after the start of the fault as seen by the increasing behavior of dc current (e.g., 'I42p' in Fig. 10(a)). FDs 12, 21, 32 and 41 are identified as 'non-potential' since they feature a negative sign of the current derivative (3) as seen by the decreasing behavior of dc current following the arrival of transient waves (e.g., 'I41p' in Fig. 10(a)).

In Step 3, the disconnector opening operations at $\approx 1.07 \mathrm{~s}$ are shown in Fig. 9(c). For P2Gnd faults, FDs shall be in open mode for a minimum time period, assumed as $40 \mathrm{~ms}$. During this period, the opening and reclosing operation of grounding switches is performed.

In Step 4, the grounding switches in the non-faulty links are closed as seen in Fig. 9(d). This operation drives the overvoltage at the non-faulty pole to zero as seen at $\approx 1.08 \mathrm{~s}$ by, for example, 'V41n' in Fig. 10(c).

Steps 5 and 6 occur in parallel for P2Gnd faults. In Step 5a, 'non-potential' FDs reclose. This is represented by a change from thick to thin line of 'FD12', 'FD21', 'FD32' and 'FD41'

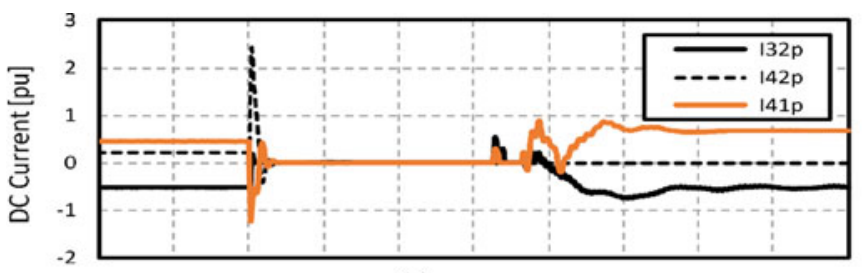

(a)

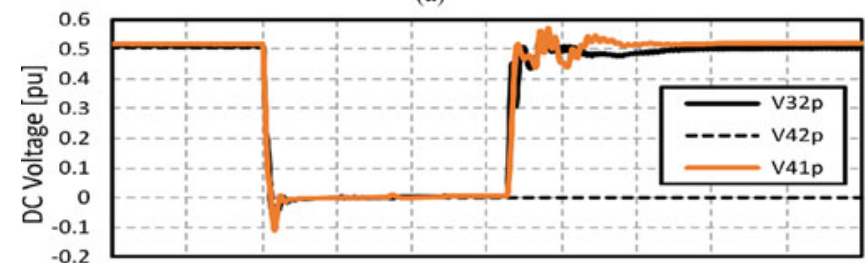

(b)

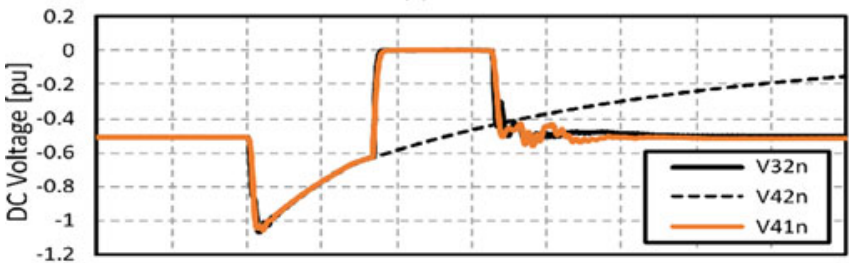

(c)

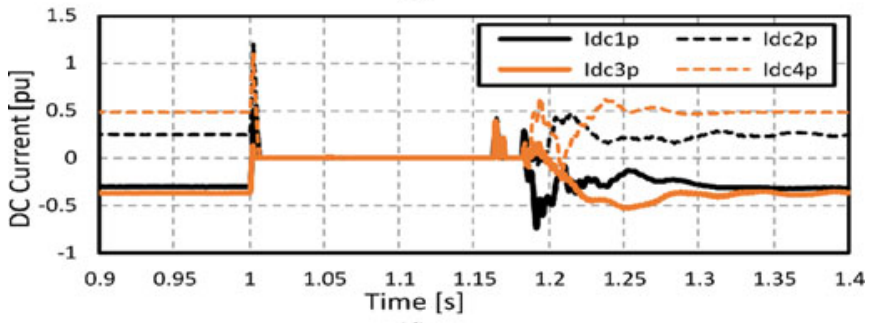

(d)

Fig. 10. (a) DC link currents, (b) dc voltage on positive pole, (c) dc voltage on negative pole and (d) dc converter current for the P2Gnd fault case.

in Fig. 9(c). In Step 6, 'potential' FDs 14 and 32 are classified as external to the faulty link as the overvoltage is suppressed, as shown by 'Vn32' and 'V41n' (Link 14) in Fig. 10(c). As a consequence, Step 7 starts. Hence, 'potential' FDs 14 and 32 reclose ('FD14' and 'FD32' in Fig. 9(c)).

The reclosing of a de disconnector leads to an ACCB reclosing order (Steps 5b and 7b), as shown in Fig. 9(b). This is followed by dc grid re-energization as observed at $\approx 1.18 \mathrm{~s}$ by 'V32p' and 'V32n' in Fig. 10(b) and (c). The next action comprises the converter de-blocking (Steps $5 \mathrm{c}$ and $7 \mathrm{c}$ ) at $\approx 1.19 \mathrm{~s}$ [see Fig. 9(a)].

At this instant $(\approx 1.18 \mathrm{~s})$, the PPS is terminated at all busbar units. The dc voltage on faulty Link 24 does not recover or exhibit a quick overvoltage suppression. As a consequence, 'potential' FDs 24 and 42 are classified as internal to faulty Link 24. Other FDs reclose due to the discrimination criteria achieved in Steps $2 b$ and 6 (see Fig. 4).

For P2Gnd faults, the recovery of the MTDC network occurs within $200 \mathrm{~ms}$ after the start of the fault. The clearance process for these faults is faster than for P2P faults mainly due to two reasons. Firstly, during the voltage shift transient period in symmetrical monopole networks, the dc fault current experiences an oscillation that may not lead to an overcurrent [12]. Secondly, 


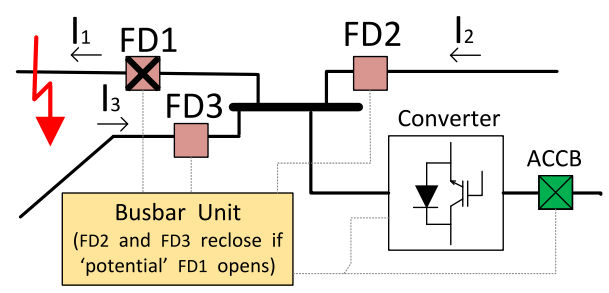

Fig. 11. Isolation failure and back-up interlock signal in a Busbar Unit.

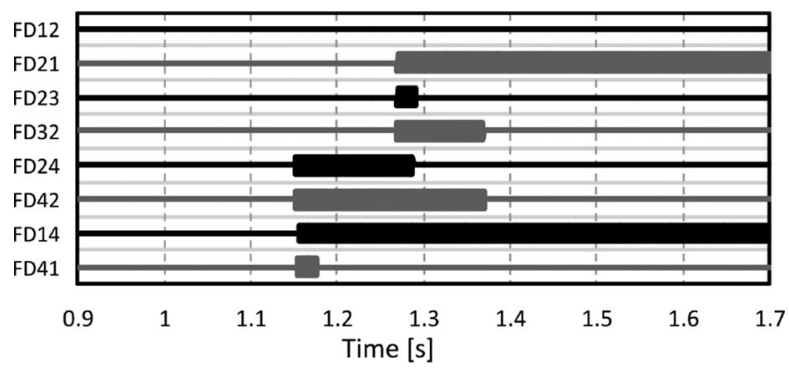

Fig. 12. State of FDs considering failure of dc disconnector 12 (P2P fault case of Section IV-A).

the high grounding impedance at the ac converter side constitutes a part of the fault discharge path and, therefore, increases the current decay rate in comparison to P2P faults [19], [22].

It should be highlighted that due to the slow operation of ACCBs, both P2Gnd and P2P faults require a considerable time to be cleared. This leads the converter current to increase for a few tens of milliseconds (e.g., up to 3 p.u. in the P2P case, as shown in Fig. 7(c)). This may not be acceptable in practical applications and, as a result, a compromise must be made between limiting the magnitude of the ac current infeed to reduce the converter rating and the design of converters to withstand high currents. Means to balance these two aspects have been briefly discussed in Section III.

\section{BACK-UP PROTECTION}

Protection schemes need to ensure safety even in the case of failure of protection devices. Fig. 11 illustrates a mal-operation case of a de disconnector. FD 1 fails to open and FDs 2 and 3 must provide back-up protection. With the PPS, opening of all FDs ensures fault isolation even in case of disconnector failure. Hence, 'FD2' and 'FD3' open and remain in open mode until the opening of 'potential' FD 1. As FD 1 remains in closed mode, the back-up FDs do not reclose and isolate the fault from the grid downstream.

The mal-operation of FDs is tested with the proposed PPS. The P2P fault case (Section IV-A) is repeated while FD 12 is ordered to remain in the close state. Back-up protection shall be ensured by the opening of FD 14. Fig. 12 shows the results for this fault case, where FD 12 remains in close state (thin line) and FD 14 is kept open with the PPS. As it can be observed, the fault is isolated and only Links 12 and 14 are out of operation. Links 23 and 42 have all FDs reclosed, leading to partial dc grid restoration.

It should be highlighted that the ACCB and converter of the busbar unit associated to the disconnector in failure operation

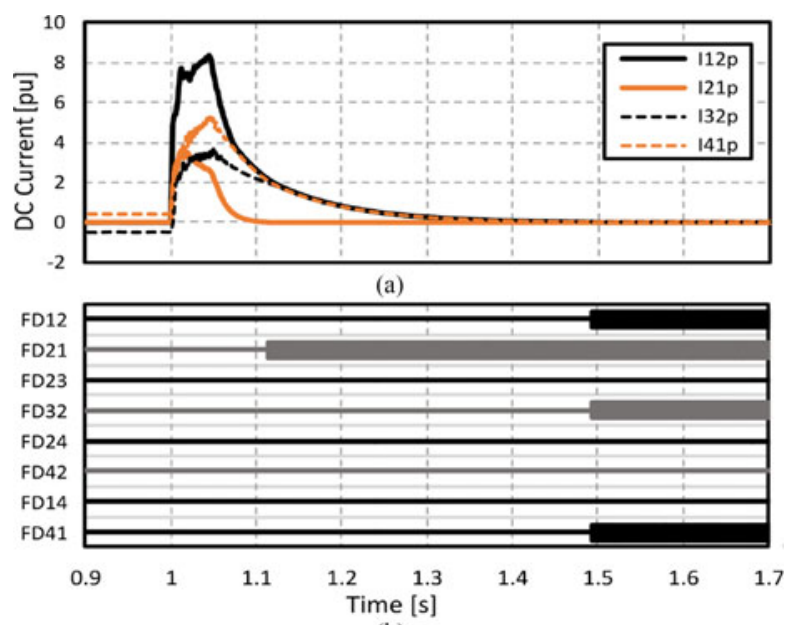

(b)

Fig. 13. (a) DC link current and (b) disconnector opening state with the "handshaking" based strategy without ACCB reclosing.

remain isolated from the network as not all FDs open. Hence, the PPS ensures back-up protection in the case of failure of FDs at the faulty link.

\section{COMPARISON With Other PROTECTION MethodS}

\section{A. Performance of PPS Against the "Handshaking" Method}

In the conventional "handshaking" method, network restoration occurs after a time delay (assumed as $100 \mathrm{~ms}$ ) following the opening of a disconnector [10], [24]. This time is considered due to the operation of ACCBs. The fault must be isolated within this time after opening the first disconnector in a network. If fault isolation is not ensured, grid re-energization might re-initiate the dc fault. Such a restoration failure event is likely to happen if a disconnector opens more than 100 ms later than any other disconnector.

Fig. 13 shows the dc current and the state of FDs when a P2P fault occurs on Link 12 at $20 \mathrm{~km}$ from Relay 12 and the "handshaking" method is employed. Notice that grid restoration is not performed. This method would require the opening of 'potential' FDs, which in this case are FDs 12, 21, 32 and 41 ('FD12' 'FD21' 'FD32' 'FD41' in Fig. 11(b)). In this method, ACCB 2 would be reclosed $100 \mathrm{~ms}$ after the opening of 'FD21' at $\approx 1.21 \mathrm{~s}$. However, with such operation, the dc current from Converter 2 would feed the dc fault, leading the opening of FDs to fail. In order to avoid an increase in dc fault current, a time delay larger than $100 \mathrm{~ms}$ would be necessary to reclose ACCB 2 .

In the PPS approach, the reclosing of ACCB 2 would occur only after the opening of all FDs associated to Busbar Unit 2 and after the reclosing of one of these FDs. For this reason, the grid restoration would not compromise the fault isolation process independently of the opening time of the FDs.

It should be highlighted that while the "handshaking" method was not conceived to deal with failure of isolation devices, the PPS includes back-up protection (Section V). This capability ensures a higher reliability of the PPS in comparison to the "handshaking" method. 


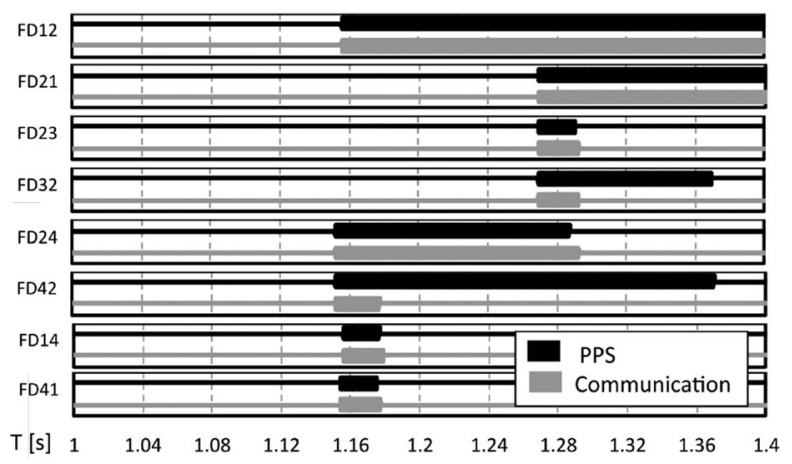

Fig. 14. Comparison of the opening and reclosing times for the PPS vs communication based strategy.

\section{B. Comparison of PPS With a Communication-Based Strategy}

A communication-based strategy is considered for protection of a network equipped with ACCBs as dc fault clearance devices. In this strategy, fault detection and fault isolation remain as in the PPS algorithm. The fault discrimination signals are achieved through a current difference algorithm [25]. All FDs receive an opening order. The reclosing order, if discriminated as external to the faulty link, is set after the opening of the 'potential' disconnector. This way, the progressive grid restoration seen in the PPS is also achieved with the communication-based strategy. Conversely, the opening order of only those FDs discriminated as internal to the faulty link would result in grid restoration at a later stage, which is a disadvantage against the PPS.

The P2P fault case in Section IV-A is repeated while the fault discrimination criterion is modified to meet the current difference algorithm presented in [25]. Fig. 14 illustrates a comparison between the opening of FDs with the PPS (in black) and the communication-based strategy (in grey). It is observed that the reclosing times of 'potential' placed at non-faulty dc links (FDs 32 and 42) are shorter with the communication-based strategy. Hence, communication algorithms allow to re-close these FDs without having to wait for the discriminative criterion based on the link voltage restoration. The links associated to these FDs, Links 23 and 24, are being restored approximately $80 \mathrm{~ms}$ earlier. This time delay corresponds to the ACCB reclosure operation, link re-energization and processing delay. Hence, link communication brings benefits in terms of reduction of grid outage after a P2P fault.

In the case of a P2Gnd fault, the fault is discriminated with current direction (as described in Section II-B) and quick overvoltage suppression detection at the non-faulty links (second criterion in Section II-E). In the communication-based strategy, fault discrimination occurs at an early stage. However, for P2Gnd faults, dc grid re-energization occurs at a similar time as with the PPS given that this is only possible after overvoltage suppression actions. Due to this, the faulty link is discriminated with both the PPS and the communication-based strategy at the same time. Hence, there is no grid outage reduction when communication is employed.

It should be emphasized that the use of communication requires a greater investment cost. There is also the possibility of mal-operation events. The arguably marginal advantages that the communication-based method brings over the PPS make of the latter an interesting and effective alternative for the protection of MTDC grids.

\section{CONCLUSION}

When ACCBs are used to clear dc side faults, P2P and P2Gnd faults lead to a temporary outage of the whole dc network. A novel protection strategy has been proposed to reduce the grid outage time through the progressive restoration of the dc grid.

The proposed strategy is able to detect a dc fault, discriminate the faulty link and restore non-faulty links in a progressive manner. Each FD is ordered to reclose in a step-by-step basis. The opening and reclosing operation of ACCBs and FDs is controlled in a busbar unit, while link communication is not required. Hence, such unit could be easily adapted to different dc grid configurations, making the PPS a robust and flexible strategy.

Benefits of the PPS include fault clearance with economic ACCBs, avoidance of dc link communication channels, a limited time of power outage in the dc network and a guaranteed backup protection. Grid restoration is faster in comparison to the "handshaking" method as it does not rely on the faulty link isolation time. The PPS has the ability to restore non-faulty dc links even if the faulty link is not completely isolated from the network. This reduces grid outage time.

Simulation results have illustrated the application of the PPS for two types of faults. For a P2Gnd fault, the dc network can be restored within $200 \mathrm{~ms}$. In the case of a P2P fault, the grid outage ranges from hundreds of milliseconds to seconds as this depends on the dc fault current decay behavior.

\section{REFERENCES}

[1] T. M. Haileselassie and K. Uhlen, "Power system security in a meshed north sea HVDC grid," Proc. IEEE, vol. 101, no. 4, pp. 978-990, Apr. 2013.

[2] D. Van Hertem and M. Ghandhari, "Multi-terminal VSC HVDC for the European supergrid: Obstacles," Renew. Sustain. Energy Rev., vol. 14, no. 9, pp. 3156-3163, 2010.

[3] V. Akhmatov et al., "Technical guidelines and prestandardization work for first HVDC grids," IEEE Trans. Power Del., vol. 29, no. 1, pp. 327-335, Feb. 2014.

[4] W. Grieshaber, J.-P. Dupraz, D.-L. Penache, and L. Violleau, "Development and test of a $120 \mathrm{kV}$ direct current circuit breaker," in Proc. CIGRE Sess., 2014, B4 301 2014.

[5] M. M. C. Merlin et al., "The alternate arm converter : A new hybrid multilevel converter with dc-fault blocking capability," IEEE Trans. Power Del., vol. 29, no. 1, pp. 310-317, Feb. 2014

[6] CIGRE B4.57 Working Group, "Guide for the development of models for HVDC converters in a HVDC grid," CIGRE, Paris, France, Tech. Rep no. 604, 2014

[7] CIGRE B4.52 Working Group, "HVDC grid feasibility study," CIGRE Paris, France, Tech. Rep. 533, 2013.

[8] B. Rusek, K. Vennemann, J. Velasquez, K. Kleinekorte, C. Heising, and V. Staudt, "Special requirements regarding VSC converters for operation of hybrid AC/DC overhead lines," in Proc. CIGRE Sess., 2014, B4_108_2014.

[9] G. Tang, Z. He, H. Pang, X. Huang, and X.-P. Zhang, "Basic topology and key devices of the five-terminal DC grid," CSEE J. Power Energy Syst., vol. 1, no. 2, pp. 22-35, 2015.

[10] L. Tang and B.-T. Ooi, "Locating and isolating dc faults in multi-terminal DC systems," IEEE Trans. Power Del., vol. 22, no. 3, pp. 1877-1884, Jul. 2007. 
[11] H. Dong, Z. Xu, P. Song, G. Tang, Q. Xu, and L. Sun, "Optimized power redistribution of offshore wind farms integrated VSC-MTDC transmissions after onshore converter outage," IEEE Trans. Ind. Electron., vol. 64, no. 11, pp. 8948-8958, Nov. 2017.

[12] P. Wang, X. P. Zhang, P. F. Coventry, R. Zhang, and Z. Li, "Control and protection sequence for recovery and reconfiguration of an offshore integrated MMC multi-terminal HVDC system under DC faults," Int. J. Electr. Power Energy Syst., vol. 86, pp. 81-92, 2017.

[13] C. D. Barker, R. S. Whitehouse, A. G. Adamczyk, and M. Boden, "Designing fault tolerant HVDC networks with a limited need for HVDC circuit breaker operation," in Proc. CIGRE Meeting 2014, 2014, pp. 1-6.

[14] European Commission, "Commission Regulation (EU) 2016/1447 of 26 August 2016 establishing a network code on requirements for grid connection of high voltage direct current systems and direct current-connected power park modules," Off. J. Eur. Union, vol. L 241, pp. 1-65, 2016.

[15] V. De Andrade and E. Sorrentino, "Typical expected values of the fault resistance in power systems," in Proc. IEEE/Power Energy Soc. Transm. Distrib. Conf. Expo. Latin Amer. T D-LA, 2010, pp. 602-609.

[16] L. Ronström, L. Hoffstein, R. Pajo, and M. Lahtinen, "The Estlink HVDC light transmission system," in Proc. Secur. Rel. Electr. Power Syst. CIGRÉ Reg. Meet., Tallinn, Estonia, 2007, pp. 1-7.

[17] J. Lundquist, C. Engelbrecht, E. Thunberg, V. Dubickas, H. Jansson, and T. Worzyk, "Lightning impulse test levels for extruded HVDC cable systems," in Proc. CIGRE Sess., 2014, B1_111_2014.

[18] T. Kristian, Y. Yongtao, D. Jovcic, S. Dennetiere, J. Jardini, and H. Saad, (CIGRE Working Groups B4-58 and B4-57), "The CIGRE B4 DC Grid Test System," in Electra, 270, 2013.

[19] A. Adamczyk, C. Barker, and H. Ha, "Fault detection and branch identification for HVDC grids," in Proc. 12th IET Int. Conf. Develop. Power Syst. Protect., IET, 2014.

[20] B. Gustavsen, J. A. Martinez, and D. Durbak, "Parameter determination for modeling system transients Part II: Insulated cables," IEEE Trans. Power Del., vol. 20, no. 3, pp. 2045-2050, Jul. 2005.

[21] D. Schmitt, Y. Wang, T. Weyh, and R. Marquardt, "DC-side fault current management in extended multiterminal-HVDC-grids," in Proc. Int. MultiConf. Syst. Signals Devices, 2012, pp. 1-5.

[22] M. K. Bucher and C. M. Franck, "Contribution of fault current sources in multi-terminal HVDC cable networks," IEEE Trans. Power Del., vol. 28, no. 3, pp. 1796-1803, Jul. 2013.

[23] C. C. Davidson, R. S. Whitehouse, C. D. Barker, J.-P. Dupraz, and W. Grieshaber, "A new ultra-fast HVDC circuit breaker for meshed DC networks," in Proc. 11 th IET Int. Conf. AC DC Power Transm., Birmingham, U.K., 2015, pp. 1-7.

[24] L. Tang, "Control and protection of multi-terminal DC transmission systems based on voltage-source converters," Ph.D. dissertation, Dept. Elect. Comput. Eng., McGill Univ., Montreal, QC, Canada, 2003.

[25] J. Descloux et al., "HVDC meshed grid: Control and protection of a multiterminal HVDC system," in Proc. CIGRE Sess., 2012, B4_308_2012.

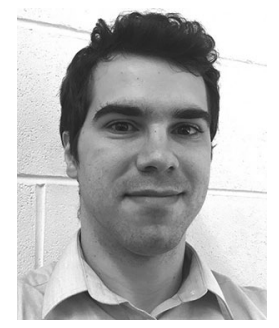

Rui Dantas was born in Barcelos, Portugal, in 1990 He received the combined B.Sc. and M.Sc. degrees in electrical and computer engineering from the Faculty of Engineering of the University of Porto, Porto, Portugal, in 2013. He is currently working toward the $\mathrm{Ph} . \mathrm{D}$. degree in dc grid discriminating protection in the School of Engineering, Cardiff University, Wales, U.K. His research interests include power system protection and $\mathrm{HVdc}$ transmission.

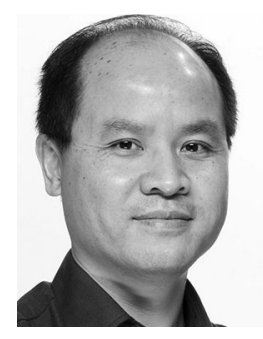

Jun Liang (M'02-SM'12) received the B.Sc. degree in electrical power engineering from Huazhong University of Science and Technology, Wuhan, China, in 1992, and the M.Sc. and Ph.D. degrees from China Electric Power Research Institute, Beijing, China, in 1995 and 1998, respectively. From 1998 to 2001, he was a Senior Engineer with China Electric Power Research Institute. From 2001 to 2005, he was a Research Associate at Imperial College London, U.K. From 2005 to 2007, he was a Senior Lecturer at the University of Glamorgan, Wales, U.K. He is currently a Professor at the School of Engineering, Cardiff University, Cardiff, U.K. His research interests include HVdc, FACTS devices, power system stability and control, power electronics, and renewable power generation.

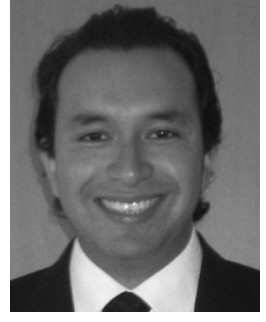

Carlos Ernesto Ugalde-Loo (M'02) was born in Mexico City. He received the B.Sc. degree in electronics and communications engineering from Monterrey Institute of Technology and Higher Education, Monterrey, Mexico, in 2002, the M.Sc. degree in electrical engineering from Instituto Politcnico $\mathrm{Na}-$ cional, Mexico City, Mexico, in 2005, and the Ph.D. degree in electronics and electrical engineering from the University of Glasgow, Scotland, U.K., in 2009. In 2010, he joined the School of Engineering at Cardiff University, Wales, U.K., and is currently a Senior Lecturer in Electrical Power Systems. His research interests include power system stability and control, grid integration and control of renewables, $\mathrm{HVdc}$ transmission, modeling of dynamic systems, and multivariable control.

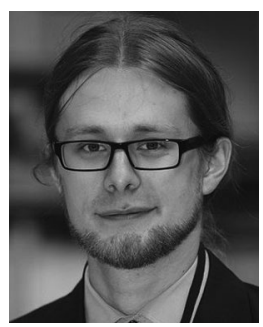

Andrzej Adamczyk received the combined B.Sc. and M.Sc. degrees in electrical and engineering from the Lublin University of Technology, Lublin, Poland, in 2009, the M.Sc. degree in power electronics and drives from Aalborg University, Aalborg, Denmark, and the Ph.D. degree in power system stability and wind power plants integration from Aalborg University, Aalborg, Denmark, in 2009 and 2012, respectively. Since 2013, he has been with the U.K. Grid Solutions, a GE business, where he is currently coordinating a research group on system aspects of $\mathrm{HVdc}$ transmission. His research interests include HVdc transmission, power system stability and control, as well as wind power technology.

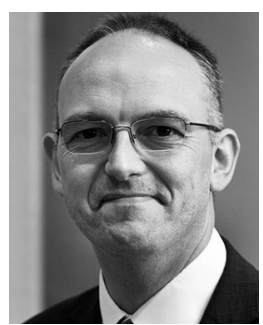

Carl Barker received the B.Eng degree from Staffordshire Polytechnic, Stoke-on-Trent, U.K., and the M.Sc. degree from Bath University, Bath, U.K. He joined GEs Grid Solutions, Stafford, U.K., in 1989, initially working on the design and development of individual HVdc and SVC projects then becoming System Design Manager, responsible for all technical aspects of $\mathrm{HVdc}$ projects. He is currently a Consulting Engineer within the business providing technical support across many activities. He is a Chartered Engineer in the U.K. and an Honorary Visiting Professor at Cardiff University, Cardiff, U.K. He is a member of the IET, U.K. and the regular member for CIGRE B4 for the U.K.

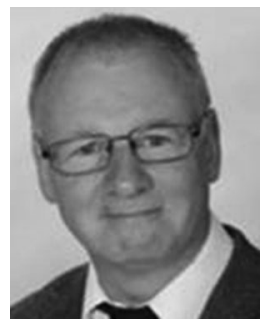

Robert Whitehouse received the B.Sc. degree in electrical and electronic engineering from North Staffordshire Polytechnic, Stoke-on-Trent, U.K., in 1979 and completed his apprenticeship with GEC Power Transformers in 1980. In 1981, he joined the GEC Power Transmission Division (now GE Grid Solutions), working in the HVdc Simulator Laboratory, carrying out studies for the IFA 2000 Cross Channel Link and designing, developing, and on-site commissioning the control hardware. In the following 35 years, he went on to manage the simulator laboratory and develop the control systems for back-to-back and transmission HVdc schemes, SVC schemes, and other power-electronic applications. His role included on-site technical support both during and after commissioning. He is currently a Senior Lead Engineer in R\&D for Voltage Source Converter (VSC) topology's and control strategies including the application of VSC to HVdc grids. Mr. Whitehouse has presented papers to international organizations including the IET, IEEE, CEA, EPE, and CIGRE. He is currently a contributor to the CENELEC TC8X working group 6 and CIGRE working group B4-59. $\mathrm{He}$ is a Chartered Engineer and a Member of the Institute of Engineering and Technology. 